\title{
Construction of a Recombinant Eukaryotic Expression Plasmid Containing Human Calcitonin Gene and Its Expression in NIH3T3 Cells
}

\author{
Xiaolin Li, ${ }^{1}$ Guozhong Jiang, ${ }^{2}$ Dan Wu, ${ }^{3}$ Xiuli Wang, ${ }^{4}$ and Bingfang Zeng1 \\ ${ }^{1}$ Department of Orthopedic Surgery, Shanghai Sixth People’s Hospital, Shanghai Jiao Tong University, Shanghai 200233, China \\ ${ }^{2}$ Department of Pathology, The First Affiliated Hospital of Zhengzhou University, Zhengzhou 450052, Henan, China \\ ${ }^{3}$ Department of Gynecology, International Peaceful Healthcare Hospital for Women \& Children of China, Welfare Institute, \\ Shanghai Jiao Tong University, Shanghai 200230, China \\ ${ }^{4}$ Department of Orthopedic Surgery, The First Affiliated Hospital of Zhengzhou University, Zhengzhou 450052, Henan, China
}

Correspondence should be addressed to Xiaolin Li, lixiaolin@sjtu.edu.cn

Received 11 February 2009; Revised 10 May 2009; Accepted 11 June 2009

Recommended by Wuyuan Lu

Aim. To construct a recombinant eukaryotic expression plasmid containing human calcitonin (hCT) gene and express the gene in murine fibroblast NIH3T3 cells. Materials and Methods. A murine Ig $\kappa$-chain leader sequence and hCT gene were synthesized and cloned into pCDNA3.0 to form the pCDNA3.0-Ig $\kappa$-hCT eukaryotic expression vector, which was transfected into NIH3T3 cells. The mRNA and protein expressions and secretion of hCT were detected. Primarily cultured osteoclasts were incubated with the supernatant of pCDNA3.0-Igk-hCT-transfected NIH3T3 cells, and their numbers were counted and morphology observed. Results. The expression and secretion of hCT were successfully detected in pCDNA3.0-Igk-hCT-transfected NIH3T3 cells. The number of osteoclasts was decreased and the cells became crumpled when they were incubated with the supernatant of pCDNA3.0Igk-hCT-transfected NIH3T3 cells. Conclusion. A recombinant eukaryotic expression vector containing hCT gene was successfully constructed and expressed in NIH3T3 cells. The secreted recombinant hCT inhibited the growth and morphology of osteoclasts.

Copyright (c) 2009 Xiaolin Li et al. This is an open access article distributed under the Creative Commons Attribution License, which permits unrestricted use, distribution, and reproduction in any medium, provided the original work is properly cited.

\section{Introduction}

Calcitonin is a 32-residue peptide hormone produced by specialized C-parafollicular cells of the thyroid glands in mammals or by cells of the ultimobranchial glands in reptiles and fish. The nucleotide sequence and translation of human calcitonin are shown in Figure $1[1,2]$. Calcitonin plays an important role in regulating calcium and phosphorus metabolism, decreasing blood calcium concentrations and inhibiting bone resorption. Natural calcitonin and synthesized analog are widely used in clinical practice for the treatment of postmenopausal osteoporosis, Paget's disease of bone, bone pain, spinal stenosis, acute pancreatitis, and gastric ulcer $[3,4]$.

Following the increase of the proportion of the elderly people in the world, osteoporosis has become a major threat to the public health due to its high morbidity and mortality [5-9]. Low bone mass and deterioration of bone microarchitecture are the major characteristics of osteoporosis, which results in increased bone brittleness and thus is associated with an increased risk for fracture. Calcitonin is one of the effective and safe agents for the treatment of osteoporosis, along with its antalgic effect [3, 4]. Calcitonins that are used in clinical practice are mainly extracted from the gills of salmon and pig thyroid glands [10]. However, these heterologous products are short of resources and thus expensive. In addition, the heterologous calcitonins are weak antigens and antibody-related resistance occurs in 40\%-70\% of patients. Moreover, side effects have been observed even through extragastrointestinal administration [11]. Dursun et al. reported that transient or persistent nausea was experienced in about one third of patients, with diarrhea, vomit and local pain at the injection site being other side effects [12]. In addition, currently recommended nasal administration of calcitonin only reaches low concentrations in blood, but may cause squamous metaplasia in the nasal 
mucous membrane, which greatly restricts its long-term application [13].

Therefore, gene engineering techniques with human calcitonin (hCT) gene as the objective gene may provide solutions overcoming the above drawbacks seen in clinical practice. However, although there have been some studies on the synthesis of calcitonin $[14,15]$, there is little information in literature on its application in gene therapy. For this purpose, we constructed a recombinant eukaryotic expression plasmid, pCDNA3.0-Ig $\kappa$-hCT, which contains human calcitonin gene and murine $\operatorname{Ig} \kappa$-chain leader sequence. The recombinant plasmid was transferred into cells of murine fibroblast cell line, NIH3T3, and the expression and secretion of recombinant hCT in NIH3T3 cells were observed in this study.

\section{Methods}

2.1. Construction and Identification of Recombinant $p M D$ $18 T$-Ig-hCT Vector. The sequences of a murine Ig $\kappa$-chain leader sequence $[16]$ and hCT gene $[1,2]$ were divided into six fragments and used as PCR primers and templates for cDNA synthesis. The primers were as follows:

\section{$\mathrm{P}_{1}: 5^{\prime}$-CAAGCTTATGGAGACAGACACACTCCTG- CTATGGGTACTG-3', \\ $\mathrm{P}_{2}: 3^{\prime}$-TGAGGACGATACCCATGACGACGAGAC- CCAAGGTCCAAGGTGACCACTGCGC-5', \\ $\mathrm{P}_{3}: 5^{\prime}$-CAGGTTCCACTGGTGACGCGGCCCAGC- CGGCCAGGCGCGCCGTACGGGATCCGTG-3',}

$\mathrm{P}_{4}:$ 3'-GCGCGGCATGCCCTAGGCACGCCATTAGACTCATGAACGTACGACCCGTGTATG-5',

$\mathrm{P}_{5}:$ 5' -CTTGCATGCTGGGCACATACACGCAGGACTTCAACAAGTTTCACACGTTCCCCCA-3',

$\mathrm{P}_{6}: 3^{\prime}$-GTTCAAAGTGTGCAAGGGGGTTTGACGTTAACCCCAACCTCGTGGAATTAGATCTG-5',

The sequence to be synthesized was shown in Figure 1(a). A dynamic template PCR technique was used to synthesize $\operatorname{Ig} \kappa$-hCT (Figure 1(a)) $[17,18]$. The PCR program included predenaturation at $95^{\circ} \mathrm{C}$ for 5 minutes, 30 amplification cycles each consisting of denaturation at $94^{\circ} \mathrm{C}$ for 30 seconds, annealing at $55^{\circ} \mathrm{C}$ for 60 seconds, and extension at $72^{\circ} \mathrm{C}$ for 50 seconds; followed by further extension at $72^{\circ} \mathrm{C}$ for 5 minutes. The cloned cDNA fragments were ligated into the pMD 18-T vector (Promega, USA) to form pMD 18-T-Ig $\kappa$ hCT. The recombinant vector pMD18T-Ig $\kappa$-hCT was amplified in E. coli JM109 and then extracted by a DNA purification system (Promega) according to the manufacturer's instructions. The designed Ig $\kappa$-hCT was retrieved from the gel. pMD18T-Ig $\kappa$-hCT was digested by HindIII and XbaI and then evaluated by $1.5 \%$ agarose gel electrophoresis. The sequence of the recombinant Ig $\kappa$-hCT eukaryotic expression vector identified by the restriction analysis was determined by using fluorescent dideoxynuleotides on an automated DNA sequencer (Gene core Technologies Co. Ltd, Shanghai, China).
2.2. Construction of Recombinant pCDNA3.0-Ig-hCT Eukaryotic Expression Vector. The procedure of construction of the recombinant pCDNA3.0-Ig $\kappa$-hCT eukaryotic expression vector was shown in Figure 1(b). The cDNA fragment of $\operatorname{Ig} \kappa$-hCT from pMD 18-T vector was further subcloned into the pCDNA3.0 (Promega) to form a eukaryotic expression vector, pCDNA3.0-Ig $\kappa$-hCT. The recombinant expression vector pCDNA3.0-Ig $\kappa$-hCT was amplified in E. coli JM 109 and then extracted by a DNA purification system (Promega). The pCDNA3.0-Ig $\kappa$-hCT retrieved from the gel was digested by HindIII and XbaI as previously described. The digested products were evaluated by $1.5 \%$ agarose gel electrophoresis.

2.3. Transfection of NIH3T3 Cells and Screening of Stable Expressing Cell Lines. NIH3T3 (ATCC) cells were transfected with pCDNA3.0-Ig $\kappa$-hCT by liposome, Lipofectamine 2000 (Invitrogen, USA). Cells at 60-80\% confluence were transfected with DNA-liposome complex at different concentrations. After 6-hours exposure, the normal culture medium, Dulbecco's Modified Eagle Media (DMEM), supplanted with $10 \%$ fetal bovine serum (Gibco, USA) was added into cells. Forty eight hours later, cells were exposed to 200, 400, 600, 800,900 , and $1000 \mu \mathrm{g} / \mathrm{mL}$ G418 (Gibco, USA), respectively, with 3 days for each concentration [2]. After 18 days of selection, G418-resistant clones were randomly picked up, and cultured in the medium containing $800 \mu \mathrm{g} / \mathrm{mL}$ G418. Single clones were transferred into and cultured in the medium with G418 concentration being reduced to $0.5 \mu \mathrm{g} / \mathrm{mL}$. Thus, hCT-transfected cells were stable selected cell lines from single clones. NIH3T3 cells that were transfected with pCDNA3.0 were used as controls.

2.4. Expression of hCT mRNA as Determined by RT-PCR. To demonstrate the mRNA expression of Ig $\kappa$-hCT mediated by pCDNA3.0-Igk-hCT vector in NIH3T3 cells, totally cellular RNA was extracted from the NIH3T3 cells by TRIzol method. First strand cDNA was performed by an AMV transcriptase kit (Promega) according to the manufacturer's instructions. The sequences of primers used for the detection of Ig $\kappa$-hCT were $5^{\prime}$-TAATACGACTCACTATAGGGAGA$3^{\prime}\left(5^{\prime}\right.$-sense) and $5^{\prime}$-ACTCGTATCATCCTHCCGAA- $3^{\prime}\left(3^{\prime}\right.$ antisense) with a product of $212 \mathrm{bp}$. For the detection of $\beta$-actin mRNA, we use a $5^{\prime}$-sense primer $\left(5^{\prime}\right.$-GGGAAATCGTGCGTGACAT- $3^{\prime}$ ) and a $3^{\prime}$-antisense primer (5'-TCAGGAGGAGCAATGATCTTG- $3^{\prime}$ ), with a product of $385 \mathrm{bp}$. PCR program was predenaturation at $95^{\circ} \mathrm{C}$ for 5 minutes, and then 30 cycles each consisting of denaturation at $95^{\circ} \mathrm{C}$ for 50 seconds, annealing at $55^{\circ} \mathrm{C}$ for 50 seconds, extension at $72^{\circ} \mathrm{C}$ for 50 seconds, and an extension at $72^{\circ} \mathrm{C}$ for 7 minutes. PCR products were electrophoresed on a $1.5 \%$ ethidium bromide-stained agarose gel.

\subsection{Detection of Expression and Secretion of hCT Protein in NIH3T3 Cells}

2.5.1. Immunohistochemistry. pCDNA3.0Igk-hCT-transfected, nontransfect ed and pCDNA3.0-transfected NIH3T3 cells were cultured in 6-well plates $\left(1 \times 10^{6} / \mathrm{mL}\right)$. One slide 


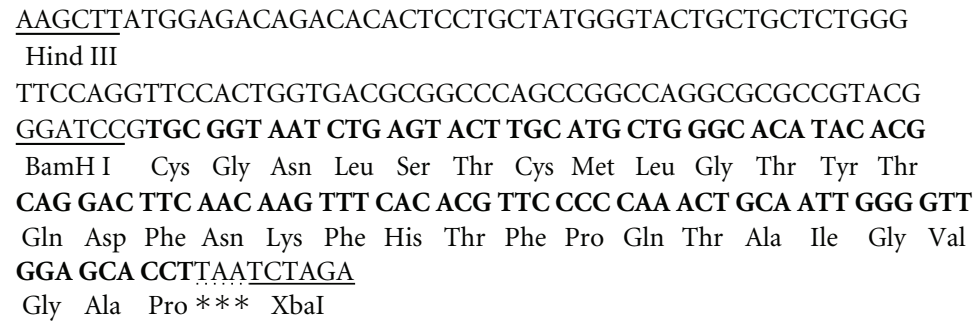

(a)

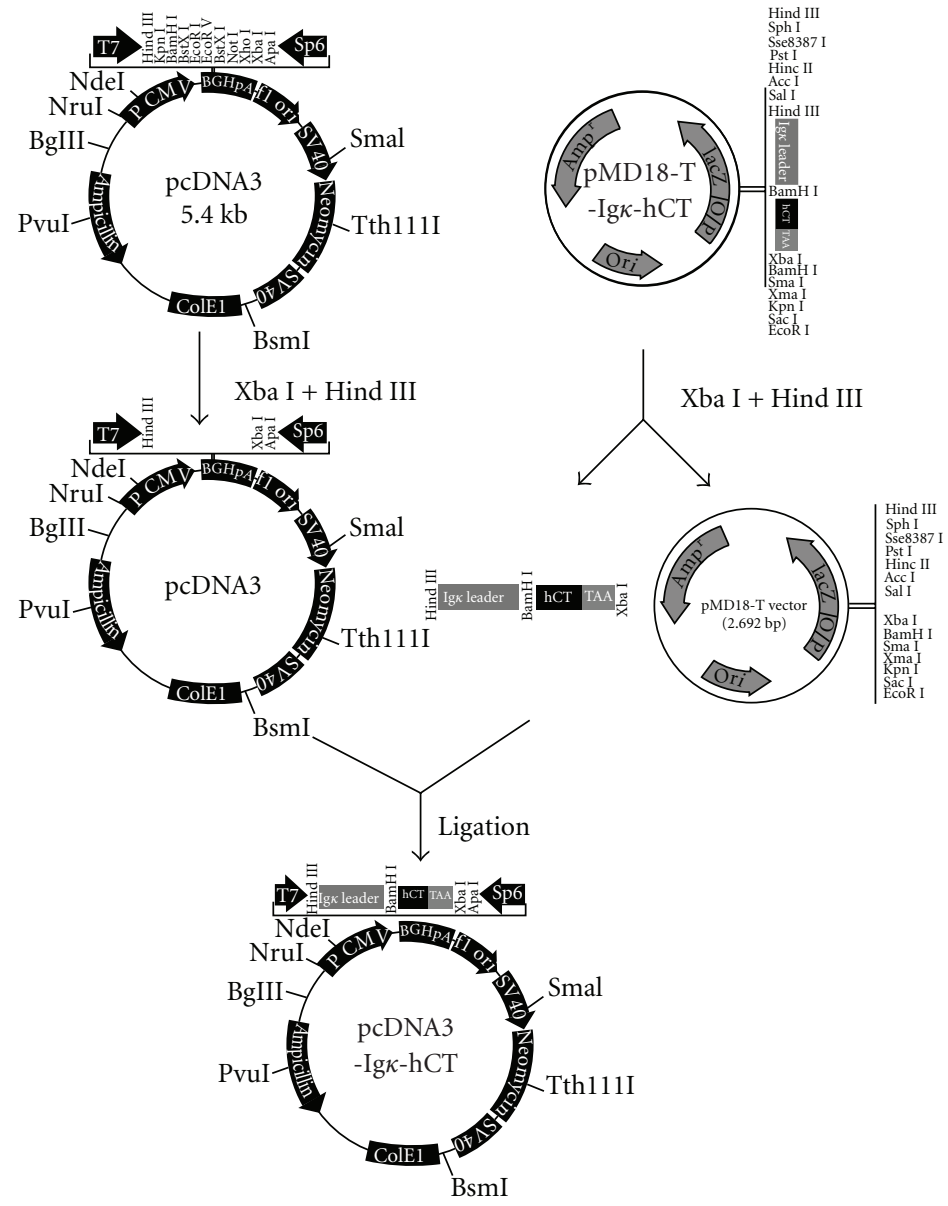

(b)

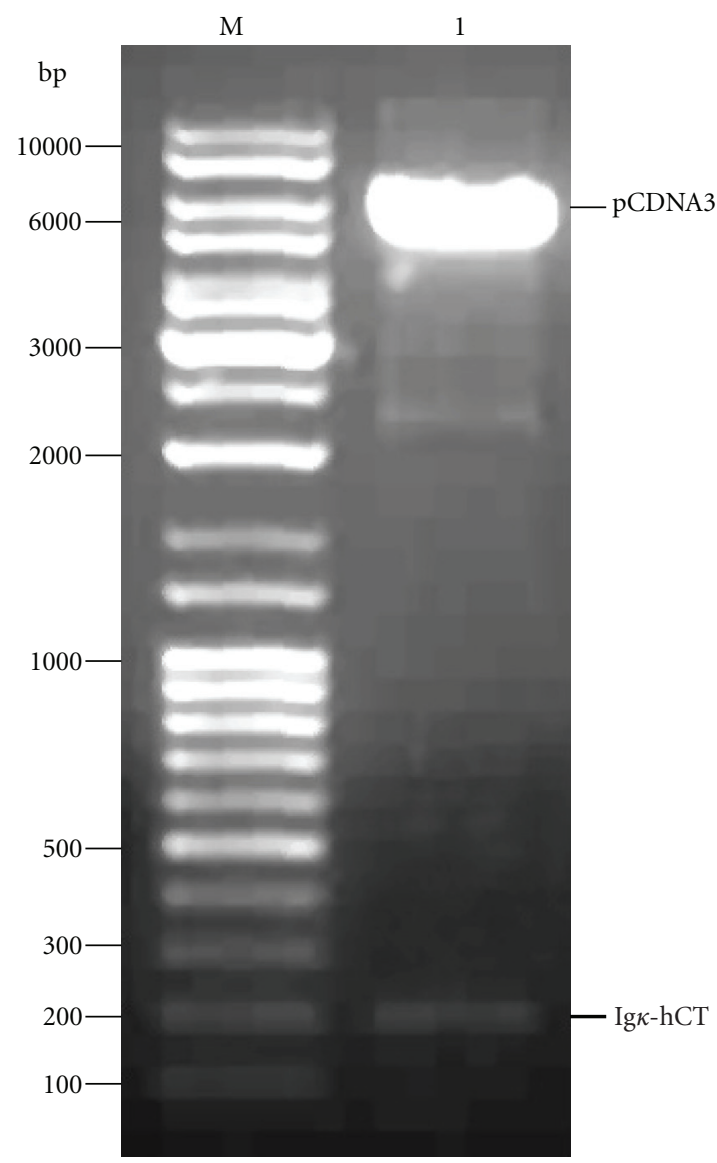

(c)

FIgURE 1: Construction and identification of recombinant pCDNA3.0-Ig $\kappa$-hCT eukaryotic expression vector. (a), The sequences that need to be synthesized. The recognition sequences for HindIII, BamHI and XbaI restriction enzymes are shown underline. The stop codon is shown asterisk under it. The DNA sequence of hCT is shown in boldface and italics, and the translated amino acids are under it. (b), Construction procedures of the recombinant pCDNA3.0-Ig $\kappa$-hCT eukaryotic expression vector. (c), Electrophoresis of recombinant plasmid pCDNA3.0$\operatorname{Ig} \kappa$-hCT digested with HindIII and XbaI.

was put in each well of six-well plates for 24 hours to grow NIH3T3 cells. Then, immunohistochemistry was performed on ethyl alcohol/acetone-fixed slides by immunohistological kit for hCT (Zhongshan Golden Bridge, Beijing, China).

2.5.2. Western Blotting. Supernatant of cultured pCDNA3.0Igk-hCT-transfected NIH3T3 cells were subjected to Western blotting after 10 fold condensation by lyophilization, with
pCDNA3.0-transfected NIH3T3 cell culture enriched supernatant being used a control. After electrophoresis and transfer of samples onto nitrocellulose membrane (Amersham Biosciences Inc. Piscataway, USA), the blots were probed with the following antibodies: rabbit antihCT (Chemicon International Inc., Temecula, USA) and goat antirabbit IgGHRP (Chemicon International Inc.). Films were developed by the chemiluminescence method. 


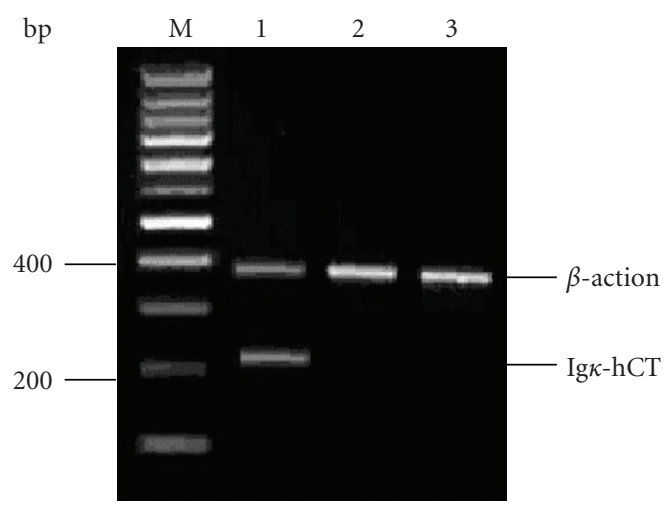

(a)

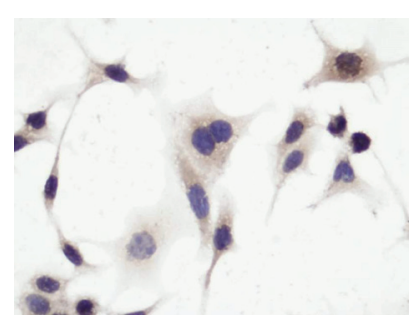

(b1)

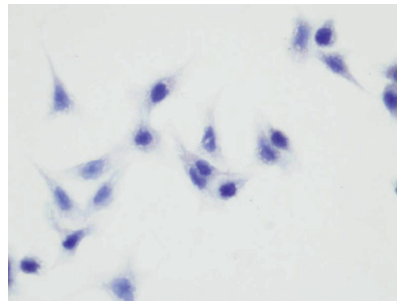

(b2)

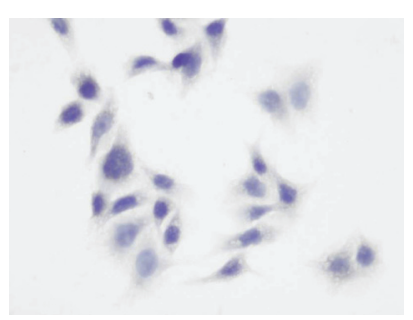

(b3)

(b)

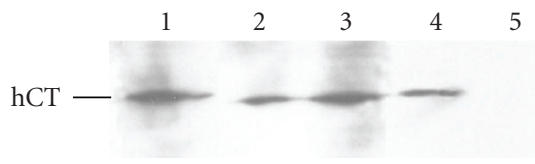

(c)

FIGURE 2: Expression of hCT mRNA and protein in NIH3T3 cells. (a). Ig $\kappa$-hCT mRNA expression in NIH3T3 cells by RT-PCR. Lane M: marker; Lane 1: RT-PCR products from pCDNA3.0-Ig $\kappa$-hCT-transfected NIH3T3 cells; Lane 2: RT-PCR product from pCDNA3.0transfected cells (negative control); Lane 3: RT-PCR product from nontransfected cells. (b), Immunohistological staining of hCT protein in pCDNA3.0-Ig $\kappa$-hCT-transfected (b1), nontransfected (b2) and pCDNA3.0-transfected NIH3T3 cells (b3). All magnification $\times 200$. (c). Western blotting showing hCT protein was detected in pCDNA3.0-Igk-hCT-transfected cells (lanes 1-4), but not in pcDNA3.0 transfected cells (lane 5).

2.5.3. Radioimmunoassay. pCDNA3.0-Igk-hCT-transfected, nontransfected and pCDNA3.0-transfected NIH3T3 cells were cultured in 6 -well plates $\left(1 \times 10^{6}\right.$ cells $\left./ \mathrm{mL}\right)$. The culture medium was replaced with a serum-free medium 24 hours later. After the cells were cultured for 24 hours, secretion of hCT in the supernatant was measured with a commercial hCT detection kit (Cehmclin, Beijing, China) by using the radioimmuniassay method.

2.6. In Vitro Effect of Expressed hCT on Osteoclasts. pCDNA 3.0-Igk-hCT-transfected, nontransfected and pCDNA3.0transfected NIH3T3 cells were cultured in 6 -well plates $(1 \times$ $10^{6} / \mathrm{mL}$ ) for 24 hours. Then, primarily isolated osteoclasts were settled onto the 6-well plates and cocultured with above NIH3T3 cells, respectively, on $15 \mathrm{~mm}$ plastic coverslips which were placed on a metallic bracket in plates, and incubated for 7 days at $37^{\circ} \mathrm{C}$. As a positive control, salmon CT (sCT, Novartis, Basel, Switzerland) was added, at concentration of $1 \mathrm{ng} / \mathrm{mL}$, into the coculture of nontransfected NIH3T3 cells and osteoclasts. To determine the identity of osteoclasts, cells were fixed and stained by using a tartrate-reisitant acid phosphatase (TRAP) stain kit (Sigma, USA) according to the manufacturer's protocol on day 7 of culture. TRAPpositive multinucleated cells with more than three nuclei were considered to be osteoclasts (Figure 3) [19]. Finally, the osteoclasts were observed under a converted microscope, and their numbers were counted and morphology observed.

2.7. Statistical Analysis. Results were expressed as means \pm standard deviation (SD). Database was set up with SPSS 10.0 software package (SPSS Inc, Chicago, IL) for analysis. The significance of differences was determined by ANOVA and Bonferroni's modification of Student's $t$-test. A difference with a $P$ value of less than.05 was considered statistically significant.

\section{Results}

3.1. Evaluation and Sequence Analysis of Recombinant Plasmid pMD 18T-Ig-hCT. The PCR product of pMD18T-Ig $\kappa$-hCT 


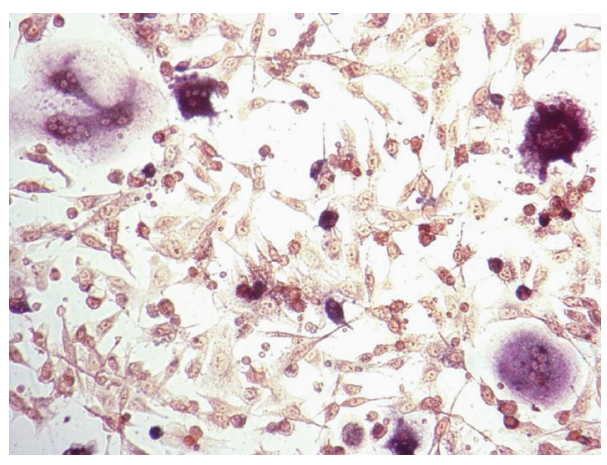

(a)

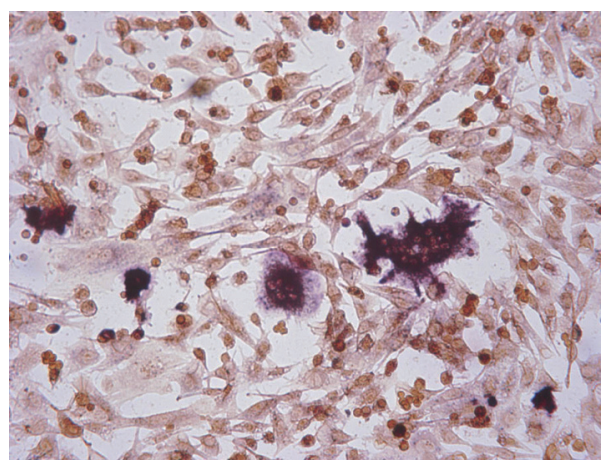

(c)

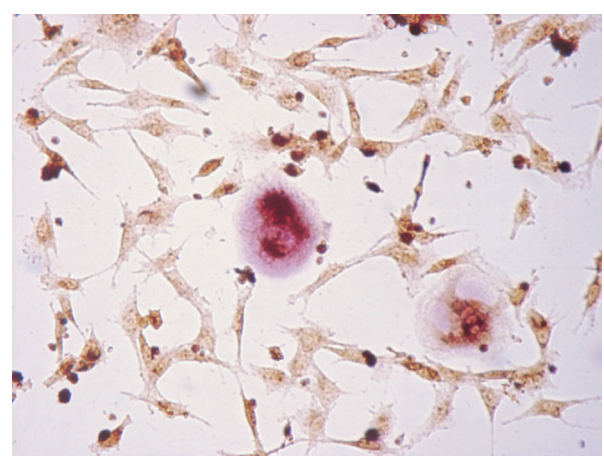

(b)

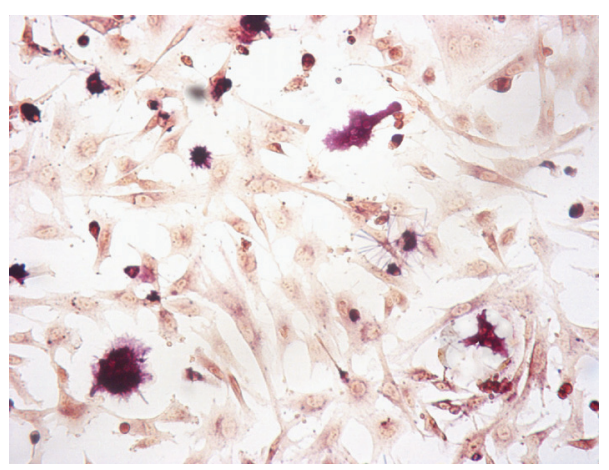

(d)

FIGURE 3: Primarily isolated osteoclasts cocultured with nontransfected (a) and pCDNA3.0-transfected (b), pCDNA3.0-Ig $\kappa$-hCT-transfected (c) NIH3T3 cells and nontransfected NIH3T3 cells plus sCT (d). TRAP staining shows that primarily isolated osteoclasts are multinucleate and spreading cells, which become crumpled when cocultured with pCDNA3.0-Ig $\kappa$-hCT-transfected.

TABLE 1: The number of TRAP-positive multinucleate cells when osteoclasts were cocultured in vitro with pCDNA3.0-Ig-hCTtransfected, and nontransfected, pCDNA3.0-transfected NIH3T3 cells, or nontransfected NIH3T3 cells plus sCT.

\begin{tabular}{ll}
\hline Group & $\begin{array}{l}\text { Number of TRAP-positive } \\
\text { multinucleate cells (means } \pm \\
\text { SD) }\end{array}$ \\
\hline $\begin{array}{l}\text { Nontransfected group } \\
\text { pCDNA3.0-transfected }\end{array}$ & $18.3 \pm 3.2$ \\
group & $16.9 \pm 2.7$ \\
pCDNA3.0-Ig $\kappa$-hCT- \\
transfected \\
group \\
$\begin{array}{l}\text { Nontransfected group plus } \\
\text { sCT }\end{array}$ \\
\hline
\end{tabular}

${ }^{*} P<.01$, compared with nontransfected group and pCDNA3.0-transfected group. ${ }^{* *} P<.01$, compared with pCDNA3.0-transfected group.

had the same length with designed $\operatorname{Ig} \kappa$-hCT gene. Ig $\kappa$-hCTcDNA was successfully inserted into pMD18T as shown by HindIII and XbaI digestion and electrophoresis (data not shown). The pMD18T-Ig $\kappa$-hCT identified by restriction analysis was sequenced. It was demonstrated that the stop codon and endonuclease sites of $\operatorname{Ig} \kappa$-hCT was successfully cloned into pMD18-T (data not shown).
3.2. Evaluation of $p C D N A 3.0-I g k-h C T$. The Ig $\kappa$-hCT cDNA was successfully ligated into pCDNA3.0 by HindIII and XbaI digestion and electrophoresis (Figure 1(c)).

3.3. Expression of hCT mRNA and Protein in NIH3T3 Cells. The $210 \mathrm{bp}$ fragment corresponding to the Ig $\kappa$-hCT cDNA amplified by RT-PCR was present only from pCDNA3.0-IgkhCT-transfected NIH3T3 cells, but not from nontransfected or pCDNA3.0-transfected cells (Figure 2(a)).

Moreover, immunocytochemistry staining showed that expression of hCT protein was detected in pCDNA3.0Igk-hCT-transfected NIH3T3 cells (Figure 2(b)1), but not in pCDNA3.0-transfected or nontransfected cells (Figures 2(b)2 and 2(b)3).

3.4. Expression and Secretion of hCT Protein in NIH3T3 Cell Culture Supernatants. Western blotting showed tha hCT was positively stained in pCDNA3.0-Igk-hCT-transfected cells, but not in pCDNA3.0-transfected or nontransfected cell (Figure 2(c)).

In addition, radioimmunoassay displayed significantly higher secretion of hCT protein in the culture supernatant $(46 \pm 7.29 \mathrm{ng} / \mathrm{mL})$ of pCDNA3.0-Igk-hCT-transfected NIH3T3 cells than those of nontransfected cells $(5.2 \pm$ $2.36 \mathrm{ng} / \mathrm{mL})$ and pCDNA3.0-transfected cells (4.8 \pm $4.31 \mathrm{ng} / \mathrm{mL}$ ) (both $P<.05)$. 
3.5. Effect of Expressed and Secreted hCT on Osteoclasts. TRAP staining showed that primarily isolated osteoclasts cocultured with nontransfected and pCDNA3.0-transfected cells were multinucleate and spreading under a converted microscope (Figures 3(a) and 3(b)). However, it was observed that osteoclasts became crumpled when cocultured with pCDNA3.0-Ig $\kappa$-hCT-transfected NIH3T3 cells and nontransfected NIH3T3 cells plus sCT group. (Figures 3(c) and $3(\mathrm{~d})$ ). The number of TRAP-positive multicleate cells was significantly fewer when the primarily isolated osteoclasts were cocultured with pCDNA3.0-Ig $\kappa$-hCT-transfected NIH3T3 cells or with nontransfected NIH3T3 cells plus sCT, than with nontransfected or pCDNA3.0-transfected cells (Table $1, P<.01$ ).

\section{Discussion}

Osteoporosis is characterized with low bone mass and deterioration of bone microarchitecture which can cause decreased bone strength and an increased risk for fracture [5-9]. Calcitonin is one of the most effective reagents for osteoporosis with antalgic activities [3, 4]. It is believed that sCT can inhibit bone resorption, reduce bone mass loss and relieve bone pain $[20,21]$. But oral or nasal administration of calcitonin can cause many side effects in osteoporosis patients $[12,13]$. Otherwise, long-term application of animal calcitonins leads to a sharp activity decrease in clinical use of osteoporosis due to the accumulation of antibodies against these heterologous calcitonins [11]. However, it is very difficult to extract bioactive calcitonin from humans. Genetic engineering strategies provide new methods for production of hCT. Therefore, gene therapy with calcitonin as an objective gene may represent an optimal resolution to overcome the above problems.

hCT cannot be secreted after synthesized in the cytoplasm because the nucleotide sequence of hCT1-32 lacks of a signal peptide, which greatly limits its application in gene therapy [22]. In the present study, we added a murine Ig $\kappa$ chain leader sequence to hCT. Thus, hCT can be secreted into the culture supernatant after it is synthesized in the cytoplasm. At the same time, the signal peptide is cleaved to avoid influencing the activities of hCT [16]. In this study, the synthetic coding sequences for Ig $\kappa$-hCT is created by ligation of six oligonucleotides. There are 19 or 20 complementary bases between $\mathrm{P}_{1}$ and $\mathrm{P}_{2}, \mathrm{P}_{2}$ and $\mathrm{P}_{3}, \mathrm{P}_{3}$ and $\mathrm{P}_{4}, \mathrm{P}_{4}$ and $\mathrm{P}_{5}$, and $\mathrm{P}_{5}$ and $\mathrm{P}_{6}$. In the first stage of PCR, $\mathrm{P}_{1}$ and $\mathrm{P}_{2}, \mathrm{P}_{3}$ and $\mathrm{P}_{4}$, and $\mathrm{P}_{5}$ and $\mathrm{P}_{6}$ were used as primers and templates to amplify $\mathrm{P}_{1-2}, \mathrm{P}_{3-4}$ and $\mathrm{P}_{5-6}$. In the second stage, $\mathrm{P}_{1-2}, \mathrm{P}_{3-4}$ and $\mathrm{P}_{5-6}$ were used as primers and templates to amplify $\mathrm{P}_{1-4}$ and $\mathrm{P}_{3-6}$. Then, they were used as primers and templates to amplify the target sequence. The integrated target sequence was synthesized after consecutive PCRs. The sequence analysis and electrophoresis of pCDNA3.0-Ig $\kappa$-hCT after digestion with HindIII and XbaI demonstrated that the objective gene $\operatorname{Ig} \kappa$-hCT was successfully cloned and ligated into the eukaryotic expression vector. The $210 \mathrm{bp}$ fragment corresponding to the Ig $\kappa$-hCT cDNA was amplified by RT-PCR, and was expressed only from pCDNA3.0-Igk-hCT-transfected NIH3T3 cells. The expression and secretion of hCT were also detected in pCDNA3.0-Ig $\kappa$-hCT-transfected NIH3T3 cells by the immunohistological method, Western blotting and the radioimmunoassay method. These observations suggest that the target fragment was successfully integrated into the genome of infected NIH3T3 cells, which was expressed successfully.

It has been shown that calcitonin inhibits bone resorption and induces osteoclast apoptosis by binding to calcitonin receptors on osteoclasts [23]. The present study confirmed these findings. We observed that primarily isolated osteoclasts cocultured with the supernatant of pCDNA3.0Igk-hCT-transfected NIH3T3 cells became crumpled and their number was decreased compared with those cocultured in nontransfected and pCDNA3.0-transfected NIH3T3 cells, which suggests its profound bioactivities such as inhibition of the growth and alteration of morphology of osteoclasts.

Many in vivo active peptides are posttranslationally amidated at the $\mathrm{C}$ terminus, which is of great importance to their activities and stability. However, we did not make any posttranslational modifications to the recombinant hCT. Eukaryotes can be used to make some modifications to products, which make it possible to directly produce amidated calcitonin. In our future research, we will aim to couple express a rat amidating enzyme and hCT-Gly in NIH3T3 cells, to obtain amidated bioactive hCT [11].

Microencapsulation is a technique that encapsules an implant into a biocompatible selective membrane made from polymers, which can insulate the implant and the immune system of the recipient, but allow small molecules, electrolytes, oxygen, and metabolites to get through the membrane [24]. Indeed, microencapsulated transplantation of cells and tissues has been demonstrated to be effective in the treatment of many diseases [25]. We propose that cell lines secreting hCT encapsulated by alginate-polylysinealginate membranes microcapsules and transplanted would constantly secret bioactive hCT for a long perioid of time in vivo, and thus represent a new strategy for the treatment of osteoporosis.

In conclusion, we successfully constructed the recombinant eukaryotic expression plasmid containing Ig $\kappa$-hCT gene. The hCT gene was effectively expressed in NIH3T3 cells and secreted into the culture supernatant with the help of the murine $\operatorname{Ig} \kappa$-chain leader sequence. The expressed and secreted hCT inhibited growth and altered morphology of primarily isolated osteoclasts. This study provides experimental data for potential gene therapeutic usage of the recombinant hCT for osteoporosis.

\section{Acknowledgment}

This study was supported by the National Natural Science Foundation of China, no. 3027131.

\section{References}

[1] R. K. Craig, L. Hall, and M. R. Edbrooke, "Partial nucleotide sequence of human calcitonin precursor mRNA identifies flanking cryptic peptides," Nature, vol. 295, no. 5847, pp. 345347, 1982. 
[2] J. Allison, L. Hall, I. MacIntyre, and R. K. Craig, "The construction and partial characterization of plasmids containing complementary DNA sequences to human calcitonin precursor polyprotein," Biochemical Journal, vol. 199, no. 3, pp. 725-731, 1981.

[3] M. Munoz-Torres, G. Alonso, and M. P. Raya, "Calcitonin therapy in osteoporosis," Treatments in Endocrinology, vol. 3, no. 2, pp. 117-132, 2004.

[4] S. Konno and S. Kikuchi, "Therapeutic effects of calcitonin on back pain in the patients with osteoporosis," Clinical Calcium, vol. 15, no. 3, pp. 168-173, 2005.

[5] NIH Consensus Development Panel, "Osteoporosis prevention, diagnosis, and therapy," The Journal of the American Medical Association, vol. 285, pp. 785-795, 2001.

[6] N. Li, P. Ou, H. Zhu, et al., "Prevalence rate of osteoporosis in the mid aged and elderly in selectedparts of China," Chinese Medical Journal, vol. 115, pp. 773-775, 2002.

[7] D. Felsenberg and S. Boonen, "The bone quality framework: determinants of bone strength and their interrelationships, and implications for osteoporosis management," Clinical Therapeutics, vol. 27, no. 1, pp. 1-11, 2005.

[8] J. M. Lane, E. H. Riley, and P. Z. Wirganowicz, "Osteoporosis: diagnosis and treatment," Journal of Bone and Joint Surgery, vol. 78, no. 4, pp. 618-632, 1996.

[9] L. S. Lim and P. Y. Takahashi, "Osteoporosis intervention in men with hip fracture," Age and Ageing, vol. 33, no. 5, pp. 507$508,2004$.

[10] L. B. Tanko, Y. Z. Bagger, P. Alexandersen, et al., "Safety and efficacy of a novel salmon calcitonin (sCT) technology-based oral formulation in healthy postmenopausal women: acute and 3-month effects on biomarkers of bone turnover," Journal of Bone and Mineral Research, vol. 19, no. 9, pp. 1531-1538, 2004.

[11] S. Merli, S. De Falco, A. Verdoliva, et al., "An expression system for the single-step production of recombinant human amidated calcitonin," Protein Expression and Purification, vol. 7, no. 4, pp. 347-354, 1996.

[12] N. Dursun, E. Dursun, and S. Yalcin, "Comparison of alendronate, calcitonin and calcium treatments in postmenopausal osteoporosis," International Journal of Clinical Practice, vol. 55, no. 8, pp. 505-509, 2001.

[13] N. N. Aldini, P. Caliceti, S. Lora, et al., "Calcitonin release system in the treatment of experimental osteoporosis. Histomorphometric evaluation," Journal of Orthopaedic Research, vol. 19, no. 5, pp. 955-961, 2001.

[14] C. Chakraborty, S. Nandi, and S. Sinha, "Overexpression, purification and characterization of recombinant salmon calcitonin, a therapeutic protein, in streptomyces avermitilis," Protein and Peptide Letters, vol. 11, no. 2, pp. 165-173, 2004.

[15] C. Chakraborty, S. S. Nandi, B. Sarkar, and S. Sinha, "Overexpression and purification of recombinant eel calcitonin and its phylogenetic analysis," Protein and Peptide Letters, vol. 12, no. 3, pp. 263-269, 2005.

[16] M. J. Coloma, A. Hastings, L. A. Wims, and S. L. Morrison, "Novel vectors for the expression of antibody molecules using variable regions generated by polymerase chain reaction," Journal of Immunological Methods, vol. 152, no. 1, pp. 89-104, 1992.

[17] C. W. Dieffenbach and G. S. Bveksler, PCR Primer: A Laboratory Manual, Cold Spring Harbor Laboratory Press, New York, NY, USA, 1995.

[18] J. Sambrook, E. F. Fritsch, and T. Maniatis, Molecular Cloning, Cold Spring Harbar Laboratory, New York, NY, USA, 2nd edition, 1989.
[19] N. Takahashi, H. Yamana, S. Yoshiki, et al., "Osteoclast-like cell formation and its regulation by osteotropic hormones in mouse bone marrow cultures," Endocrinology, vol. 122, no. 4, pp. 1373-1382, 1988.

[20] M. T. McDermott and G. S. Kidd, "The role of calcitonin in the development and treatment of osteoporosis," Endocrine Reviews, vol. 8, no. 4, pp. 377-390, 1987.

[21] S. Patel, A. R. Lyons, and D. J. Hosking, "Drugs used in the treatment of metabolic bone disease: clinical pharmacology and therapeutic use," Drugs, vol. 46, no. 4, pp. 594-617, 1993.

[22] G. J. Cote, D. T. Stolow, S. Peleg, S. M. Berget, and R. F. Gagel, "Identification of exon sequences and an exon binding protein involved in alternative RNA splicing of calcitonin/CGRP," Nucleic Acids Research, vol. 20, no. 9, pp. 2361-2366, 1992.

[23] R. Giardino, M. Fini, N. Nicoli Aldini, et al., "Effects of synthetic salmon calcitonin and alendronate on bone quality in ovariectomized rats," Minerva Medica, vol. 88, no. 11, pp. 469-477, 1997.

[24] P. L. Robert and L. C. William, "Transplantation of encapsulated cells and tissues," Surgery, vol. 121, no. 1, pp. 1-9, 1997.

[25] I. T. Tai and A. M. Sun, "Microencapsulation of recombinant cells: a new delivery system for gene therapy," The FASEB Journal, vol. 7, no. 11, pp. 1061-1069, 1993. 

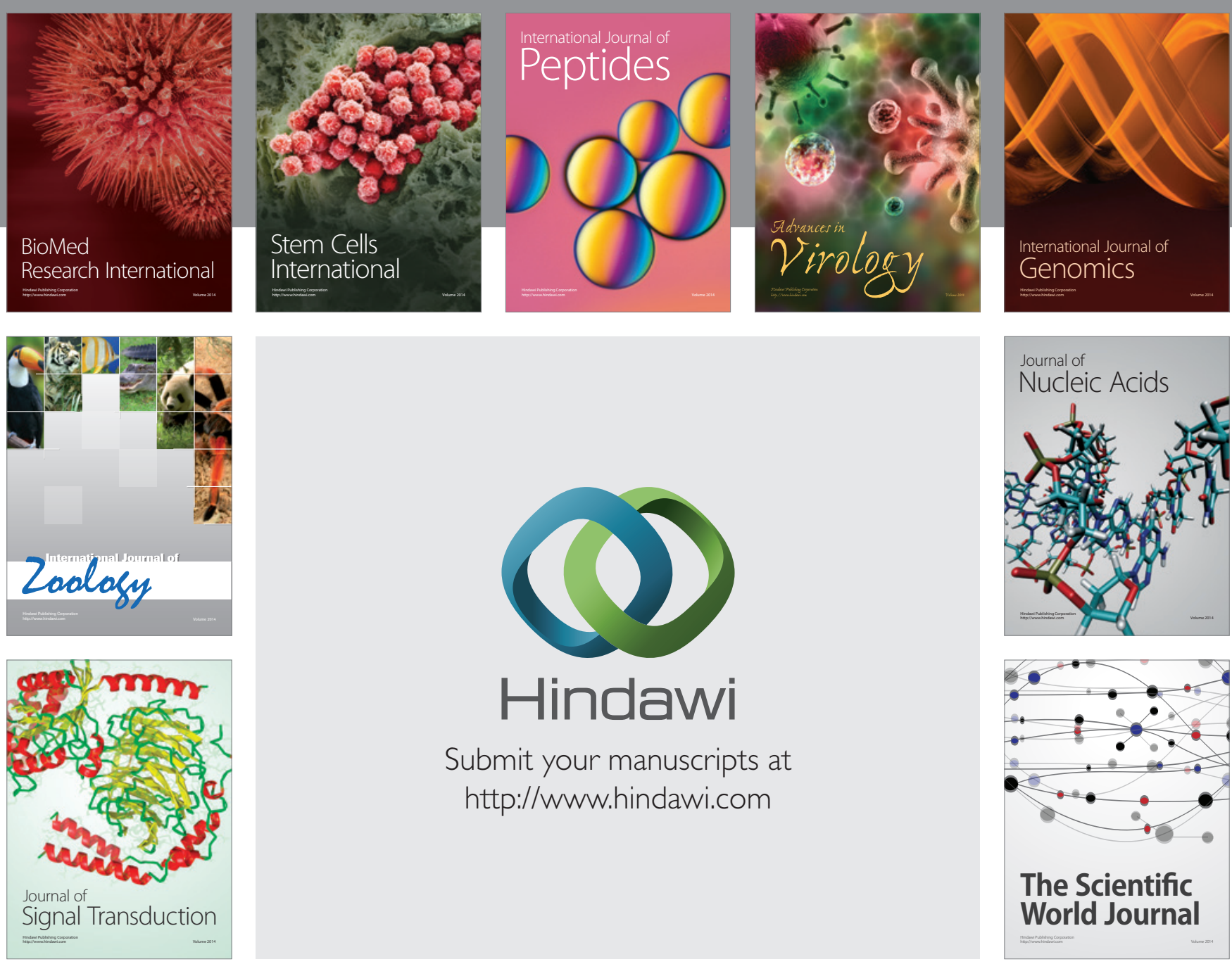

Submit your manuscripts at

http://www.hindawi.com
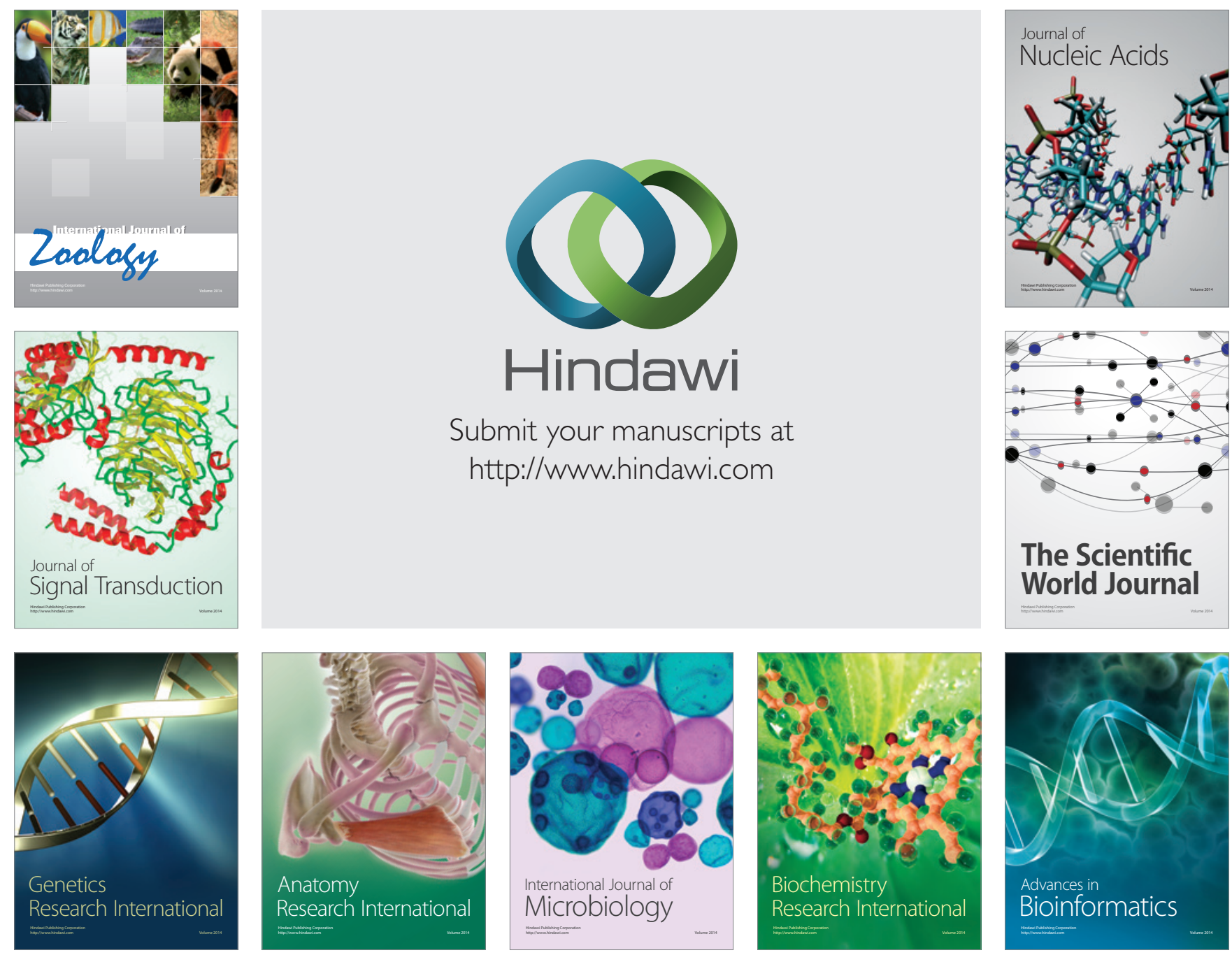

The Scientific World Journal
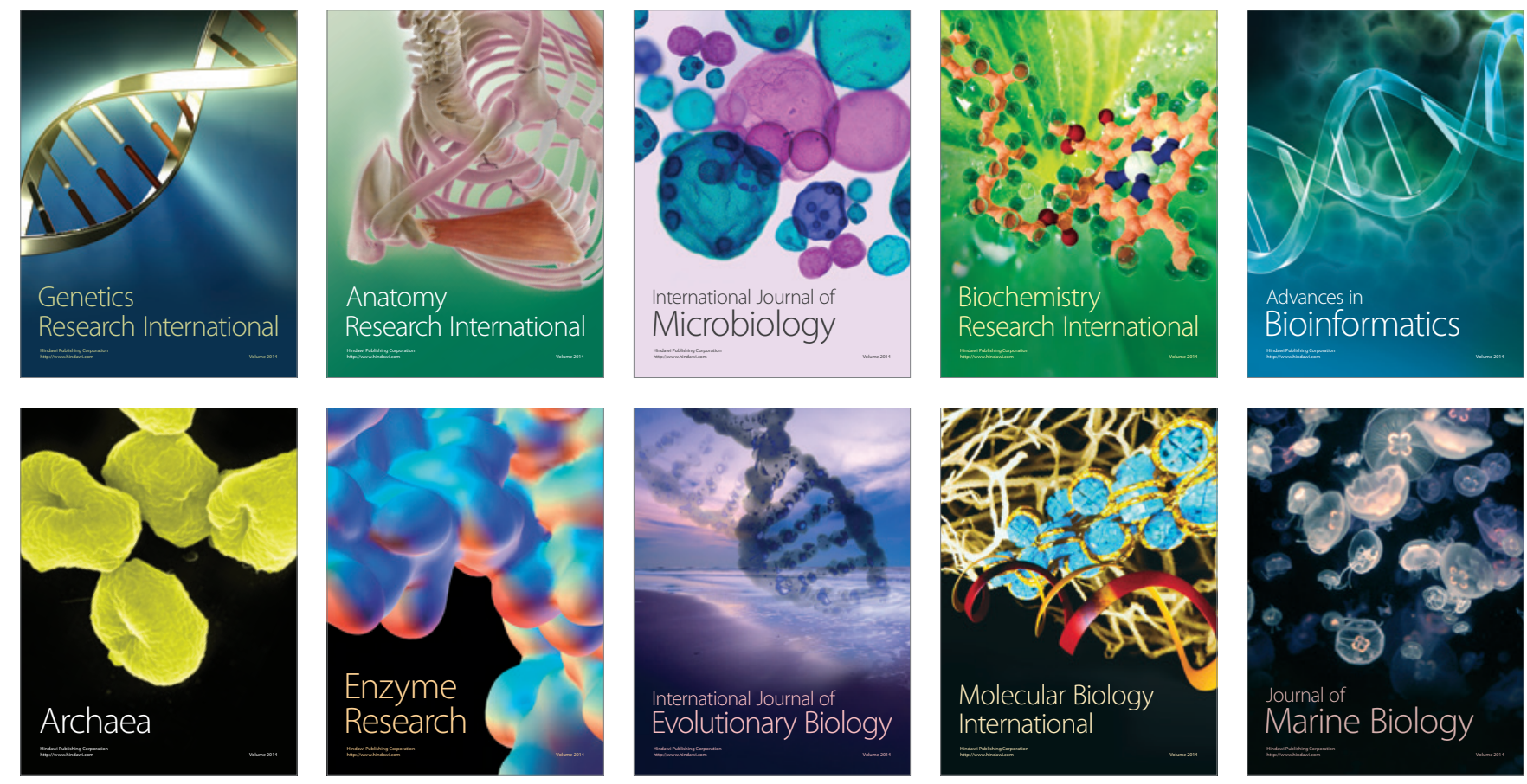